\title{
Examining the role of knowledge management and technology operating capabilities in the development of customer-centric organisational systems
}

\begin{tabular}{|c|c|}
\hline \multicolumn{2}{|c|}{$\begin{array}{l}\text { Authors: } \\
\text { Watson Munyanyi }{ }^{1} \text { (D) } \\
\text { David Pooe }\end{array}$} \\
\hline \multicolumn{2}{|c|}{$\begin{array}{l}\text { Affiliations: } \\
{ }^{1} \text { Department of Banking and } \\
\text { Finance, Greater Zimbabwe } \\
\text { University, Masvingo, } \\
\text { Zimbabwe }\end{array}$} \\
\hline \multicolumn{2}{|c|}{$\begin{array}{l}{ }^{2} \text { Department of Business } \\
\text { Management, University of } \\
\text { Johannesburg, Johannesburg, } \\
\text { South Africa }\end{array}$} \\
\hline \multicolumn{2}{|c|}{$\begin{array}{l}\text { Corresponding author: } \\
\text { David Pooe, } \\
\text { dpooe@uj.ac.za }\end{array}$} \\
\hline \multicolumn{2}{|c|}{$\begin{array}{l}\text { Dates: } \\
\text { Received: } 30 \text { Apr. } 2018 \\
\text { Accepted: } 15 \text { Jan. } 2019 \\
\text { Published: } 30 \text { Apr. } 2019\end{array}$} \\
\hline \multicolumn{2}{|c|}{$\begin{array}{l}\text { How to cite this article: } \\
\text { Munyanyi, W. \& Pooe, D., } \\
\text { 2019, 'Examining the role } \\
\text { of knowledge management } \\
\text { and technology operating } \\
\text { capabilities in the } \\
\text { development of customer- } \\
\text { centric organisational } \\
\text { systems', Acta Commercii } \\
\text { 19(2), a647. https://doi.org/ } \\
\text { 10.4102/ac.v19i2.647 }\end{array}$} \\
\hline \multicolumn{2}{|c|}{$\begin{array}{l}\text { Copyright: } \\
\text { (C) 2019. The Authors. } \\
\text { Licensee: AOSIS. This } \\
\text { is licensed under the } \\
\text { Creative Commons } \\
\text { Attribution License. }\end{array}$} \\
\hline \multicolumn{2}{|l|}{ Read online: } \\
\hline 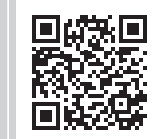 & $\begin{array}{l}\text { Scan this QR } \\
\text { code with your } \\
\text { smart phone or } \\
\text { mobile device } \\
\text { to read online. }\end{array}$ \\
\hline
\end{tabular}

Orientation: Over the years technological competence and knowledge management have grown in significance in relation to strategic management of firms.

Research purpose: The aim of the study was to examine the role of knowledge management and technology operating capabilities in the development of customer-centric organisational systems for small and medium enterprises in Zimbabwe.

Motivation for the study: The dynamism in the business environment, coupled with the proliferation in technological advancements, is forcing firms to reorient themselves, especially towards customer centrism.

Research design, approach and method: Based on a cross-sectional survey conducted on 388 firms in Zimbabwe, this study sought to investigate the influence of knowledge management capabilities and technology operating capabilities on the ability of small and medium enterprises to create customer-centric organisational systems. A five-point Likert scale questionnaire was used to collect data from simple, randomly selected small firms, and structural equation modelling was used to test the direction and significance of the proposed relationships.

Main findings: The study found that there are positive relationships between the two dimensions of knowledge management capability and one technological competence dimension.

Practical/managerial implications: Because external knowledge searches have become progressively significant for small and medium enterprises to attain and maintain a competitive advantage, the study findings demonstrate that knowledge acquisition and transformation are also essential for firms to create customer-oriented organisational systems.

Contribution/value-add: The novelty in this study is that it decomposes absorptive capacity and technological competences and assesses the individual dimensions' influence on the dependent variable, thereby enhancing exhaustive understanding while avoiding theoretical misspecifications and empirical contradictions.

Keywords: knowledge management; technology operating capabilities; customer-centric organisational systems; SMEs; knowledge acquisition capability; knowledge transformation capacity.

\section{Introduction and background}

In responses to the dynamism in the business environment and the proliferation of the Internet, corporations are being pushed to transform into customer-centric businesses. Both large and small businesses are reorganising themselves to align to the changing needs of the now more active and informed customers who desire more collaborative involvement with firms (Brodie et al. 2011:255). Today, through participation in customer forums, customers have become value co-creators and resource integrators, creating an avenue for firms to attain a competitive advantage (Hsieh et al. 2018:1054; Malshe \& Friend 2018:895). Several businesses have adopted a customercentric slant to optimise customer satisfaction by placing the customer's experience as the lead concern in product development (Montignies, Nosulenko \& Parizet 2010:592). In line with the notion of the combined scope of value co-creation the customer now performs a double-edged role, as co-producer of products and as value creator together with the firm (Grönroos \& Voima 2013:140). As a result, customers have been elevated from being passive consumers and receivers of value to being proactive co-creators (Chan, Yim \& Lam 2010:48). In this context, academics and practitioners have doubted the applicability today of classical product and geographically 
focussed organisational systems, arguing that firms must move towards customer-focussed organisational systems (Homburg, Workman \& Jensen 2000:465). It is imperative that firms not only extend their total offerings towards unified solutions that combine products and services to customer-specific solutions but also alter their existing organisational structures towards customer centrism (Gebauer \& Kowalkowski 2012:527).

For a firm to be able to create enduring customer-centric systems, it is vital that these firms be equipped with effective knowledge and technology-oriented capabilities that facilitate successful implementation of such systems. Knowledge management and technology have grown to become central strategic assets for a firm, deep-rooted in the firm's processes, culture and human resources and capable of creating a competitive advantage (Wang, Li \& Li 2013:60). On the one hand, it is largely accepted that firms that follow the two key steps in knowledge management, knowledge acquisition and knowledge transformation significantly improve their capacity to perform in areas such as innovation (Hsieh \& Chou 2018:92). In addition, small and medium enterprises (SMEs) traditionally tend to benefit substantially from concerted knowledge-based activities because they are able to access complementary resources and capabilities entrenched in their local network systems (Davenport 2005:683). On the other hand, technology has proved to facilitate internal processes like innovation at firm level, consequently improving firm competitiveness productivity and economic growth (Sobankea et al. 2014:992). In order to respond effectively to the everchanging customer need, businesses must continually make use of new and smart technologies to improve products and services (Foroudi et al. 2018:272). The technology operating capability of SMEs' employees is therefore valuable as it leads to improvements in the value to the customer while reducing the firm's cost structure. The growth in technological complexities has also led to an increase in firms' dependence on external knowledge in their business processes, making knowledge and technology complements (Hsieh \& Chou 2018:92).

While there has been a general increase in the growth in empirical literature on absorptive capacity, a concept that refers to the ability to recognise the value in novel information and knowledge and incorporate it in a firm's commercial operations (Zhai et al. 2018:318), there are significant gaps that still exist. There are limited studies that have broken down the notion of absorptive capacity into subconstructs; hence the individual role of dimensions like knowledge acquisition and knowledge transformation remains ambiguous, both in theory and in practice. Inability to recognise the different dimensions of absorptive capacity and their unique individual roles could cause theoretical misspecifications and empirical contradictions. Moreover, there is limited literature focussing on the collaborative influence of absorptive capacity individual dimensions with other variables like technology capabilities, and this limits the exhaustive development of theory and managerial practice concerning the individual dimensions of absorptive capacity. In light of the critical issues highlighted, this study conceptually broke down absorptive capacity and empirically investigated how the individual dimensions of absorptive capacity (knowledge acquisition, knowledge transformation capabilities) pull technological operating capability to influence the creation of customer-centric organisational systems. The primary contribution of this study is that it improves on the understanding of the influence of knowledge practices and support factors like technology operating capabilities (TOCs) on the development of vital customeroriented systems in SMEs.

\section{The socio-economic context of Zimbabwe}

The Zimbabwean economy has historically been dependent on the agriculture, tourism and mining sectors, and the mining sector has remained vibrant to date owing to the immense reserves of minerals like chrome, gold, coal, platinum and nickel (Simwayi \& Haseed 2011:119). From the year 2000, the country experienced a severe economic crisis, particularly following the political and social unrest that accompanied the fast-track land reform programme. The intensification of the land redistribution programme worsened relations between Zimbabwe and Western countries, leading to sharp declines in foreign direct investment inflows and economic growth and to high inflation rates (Mahembe \& Odhiambo 2016:324). Inflation figures reached unimaginably high rates of up to 500 billion percent in December 2008, transforming into hyperinflation, and as the currency continued to lose value it became difficult for businesses to continue to operate profitably and predictably (Masaka 2013:323). The hyperinflation forced many large and small firms to either close down or have their operations put under severe operational pressure. Many people lost their jobs during the hyperinflation period, and to survive many alternatively started their own businesses, resulting in the propagation of SMEs in different sectors of the economy.

In February 2009, the government of Zimbabwe officially adopted a multicurrency system, which saw the local Zimbabwean dollar being put aside as legal tender in favour of hard currencies such as the US dollar, taming close to a decade of hyperinflation (Simwayi \& Haseed 2011:199). Despite the problems associated with the multicurrency system, it managed to stabilise inflation and restore sanity, profitability and viability in the business arena (Ngwenya, Pelser \& Chivaura 2018:4). The SME sector's viability was also largely enhanced by the multicurrency system and, by 2013, was leading in terms of fostering economic and social growth (Mbizi et al. 2013:371). As stated by Mbizi et al. (2013:371), the sector accounted for 35\% of gross domestic product, $43 \%$ of total salaries and wages and employed $54 \%$ of the formal private sector employees by 2013. Because SMEs are diverse in nature, they have emerged as the engine for economic development and sustainable development in Zimbabwe. However, the SME sector in Zimbabwe 
continues to suffer several challenges including funding inadequacy, poor management, hostile government policies, lack of suitable infrastructure and poor overall economic performance (Bomani, Fields \& Derera 2015:114). Empirical research on how these SMEs can use capabilities in place of resources could help alleviate some of these challenges; hence the need for the current study.

\section{Literature review}

Absorptive capacity has been defined as the firm's ability to identify new and external knowledge, integrate it and apply it in its commercial applications (Cohen \& Levinthal 1990:128). Fundamentally, absorptive capacity encompasses four characteristic processes - knowledge acquisition, assimilation, transformation and exploitation - and these four processes are categorised further into potential absorptive capacity (acquisition and assimilation) and realised absorptive capacity (including transformation and exploitation). The decision to select knowledge transformation capability was influenced by Todorova and Durisin (2007:777), who believe that, most likely, knowledge assimilation and knowledge transformation occur in parallel rather than in successive order. This study focusses on knowledge acquisition and knowledge transformation to encompass both potential and realised absorptive capacity, hence the exploratory and transformative knowledge building blocks in businesses.

\section{Knowledge acquisition capability}

Amid accelerated product and process innovation cycles and increased competition, firms progressively need to complement internal research and development with external knowledge (Hagedoorn \& Wang 2012:1079). Knowledge is regarded as a critical organisational resource in contemporary strategic management. It is regarded as one of the most vital resources for enhancing the competitive strength of a firm, and effective management of knowledge is thus key to sustainable enterprise growth $(\mathrm{Wu} \& \mathrm{Chen}$ 2014:1150). Additionally, systematic acquisition of knowledge has become a prerequisite for effective decision-making in firms. De Arruda et al. (2017:155) argue that the more acquisition of knowledge the better the learning for a business. Knowledge acquisition is that part of knowledge management that is concerned with the critical obtaining of external knowledge to meet existing needs, exploit assets and develop new opportunities (Quintas, Lefrere \& Jones 1997:385). According to Zhou and Li (2012:1092) knowledge acquisition is related to the obtaining of knowledge through a search beyond existing sources like customers and marketplaces. Other sources of knowledge include chambers of commerce, business publications and newspapers. Knowledge is also obtainable from internal sources ( kkerman 2015:81). Those organisations that are consistent and effective in external knowledge transformation can develop better products and services than their competitors (Kocoglu, Algun \& Keksin 2015:115).

\section{Knowledge transformation capacity}

In terms of the dynamic capabilities view, the basis of a firm's performance lies in its ability to transform knowledge, which is a significant constituent of absorptive capacity (Zahra \& George 2002:188). It denotes the capacity to change and enhance the organisational routines that enable the combination of existing and newly acquired knowledge (Zahra \& George 2002:188). The transformation of knowledge normally occurs in a societal context, and to develop knowledge transformation capabilities a firm must strengthen its interfirm relationships (Chang, Gong \& Peng 2012:929).Eventually, the firm benefits from improved transformation capabilities as effective knowledge transformation quickens the absorption of new ideas, efficient integration of ideas into organisational systems and innovation, eventually triggering superior business performance. The process of transforming knowledge from being an individual viewpoint into being a knowledge rooted in firm strategies requires a blend of business practices and decision-making processes (Krome 2014:106). The process of developing knowledge transformation capabilities involves particular knowledge-sharing practices that enable insightful processes to be used for strategic initiatives. These practices include the SME's ability to apply knowledge obtained from the market into business operations, and this is what this study investigated. Knowledge transformation capacity is attained when the firm adopts new external knowledge, attained through assimilation, into the firm's activities mixed with internal knowledge, thereby resulting in a competitive edge (Rundquist 2012:18).

\section{Technology operating capability}

Globally, firms are making use of technology to undertake operational transactions, activities and processes as a way of reducing costs and increasing efficiency. The acquisition and application of novel technology in the firm's operational procedures promotes the development of new products and new customer acquisition, thus cultivating better returns for the business (Minguela-Rata, Fernandez-Menendez \& FossasOlalla 2014:439). Darbanhosseiniamirkhiz and Ismail (2012:113) argue that firms that apply new technologies achieve flexibility, responsiveness and quality; hence SMEs must focus their longterm strategic plans towards technology. Those firms that operate in dynamic industries can make use of technology to create technology-based innovations that are critical for a sustainable competitive advantage (Operti \& Carnabuci 2014:1042). Technology operating capability involves the firm's capability to employ technological systems such as enterprise resource planning systems and other information and technology motivated systems for the benefit of the firm (Harison \& Boonstra 2008:283). For firms to be regarded as technologically capable, they should possess the capacity to rightfully employ beneficial technologies while ensuring product flexibility and inventory management (Salomon \& Jin 2010:1089). The challenge of adopting and efficiently operating the right technologies remains evident in most firms operating in developing countries, and this study aids in improving the adoption and operation of new technologies 


\section{Customer-centric organisational systems}

As the business world becomes more and more complex and chaotic, firms must deal with a variety of uncertainties and challenges including the fact that customers have become more demanding, expecting on-time delivery, high quality goods and reasonable prices (Yeung et al. 2018:190). This situation is exacerbated by the fact that customers now have many buying options and can quickly switch to other firms (Güçdemir \& Selim 2017:100). Customer centricity has become central to the success of firms alongside other factors like technology, networking and external knowledge absorption (Youssef et al. 2018:146). It is defined as the general alignment towards customers' needs and satisfaction as a priority in organisational strategic decision-making (Smirnova, Rebiazina \& Frösén 2017:457). Customer-centric organisational systems relate to the alignment towards the provision of solutions to the firm's customers through a comprehensive understanding of customers and competitors across the firm's divisions (Frankenberger, Weiblen \& Gassmann 2013:673). Given the complexity in global competition and the increasing demand by customers for high-quality and low-priced goods, firms are better off altering their organisational systems alongside a shift in business activities to low utility cost locations and uncomplicatedness in communication and transport (Kayvanfar et al. 2018:69). Customer centrism should be embedded in the firm's cognitive systems as the customer-related processes that guide business activities, and because firms cannot rely on novel services only they must resort to aggressive customercentric strategies to attain competitiveness (Postigo-Boix \& Melús-Moreno 2018:571). The creation of customer-centric organisational systems, which is central to this study, acts an acknowledgement of the significance of customer centrism to SMEs.

\section{Conceptual framework and hypothesis development}

A review of related literature produced an overview of the research constructs, enabling the development of detailed constituent hypotheses. The following conceptual model conforms to the provisions of the dynamic capabilities theory and to the knowledge-based view, which posits that a firm's capabilities and alignments are dependent upon the firm's ability to acquire and transform knowledge (Grant 1996:110).

Several scholars have conformed to the notion that the strategies of the firm are articulated with the help of external knowledge accumulated by the firm and technology (Frankenberger et al. 2013:678; Kocoglu et al. 2015:115; Zahra \& George 2002:188). Knowledge management practices and technology usage impact positively on the firm's internal structures and strategic goals, basically altering the firm's strategy formulation capabilities (Zahra \& George 2002:188).

\section{Knowledge acquisition capacity and customer-oriented organisational systems}

Uncertainty in the business environment, coupled with the increase in global competition, have produced inconsistencies in firm profits, and many firms have been forced to cut their operational costs and find new ways to foster growth (Frankenberger et al. 2013:678). This has been the case with SMEs operating in Zimbabwe. Notably, the need to maintain productive customer relationships and implement customercentric systems to customer satisfaction have become more significant (Enz \& Lambert 2015:25). Central to the process of customer relationship management is external knowledge that gives organisational insights into customer conduct, needs and preferences. Knowledge acquisition capability is a decisive organisational competence that empowers organisations to cope with different circumstances and changes in competitiveness (Mishra et al. 2018:49). Knowledge enables the design of personalised business processes, which in turn will aid in leveraging customer retention and preserve competitiveness (Frankenberger et al. 2013:678). Firms that possess knowledge acquisition capability can effectively formulate critical organisational strategies and develop better products compared to their competitors (Kocoglu et al. 2015:115). Through distinct knowledge acquisition, firms can improve their internal processes and units, as well as facilitate better strategic policymaking (Behfar, Turkina \& Burger-Helmchen 2018:167). It is therefore hypothesised that:

$\mathbf{H}_{\mathbf{1}}$ : There is a positive and significant relationship between knowledge acquisition capacity and customer-oriented organisational systems.

\section{Knowledge transformation capacity and customer-oriented organisational systems}

In order to attain a sustainable competitive advantage, firms need to have deeper insight into their customers, because by appreciating customer needs firms are able to improve customer relationships (Thakur \& Workman 2016:4095). The global market is undergoing extensive transformation, and globalisation has increased accessibility of markets by consumers. It has become less expensive for customers to switch between firms especially in the retail market, and consequently it has become imperative for firms to focus on maintaining good relations with customers (Chiang 2018:525). However, the process of ensuring good customer relations has remained unclear with respect to the antecedents of sustainable customer-centric organisational systems. The knowledge management literature suggests that sales knowledge and knowledge on competition are often a reliable basis for customer relationship management if accurately shared among the firm's functional units (Bortoluzzi et al. 2018:215). Extensive knowledge transformation capability has been found to be efficient in aiding firms to identify new systems, helping companies leverage new knowledge to improve product performance, enhance product quality and cut costs (Korhonen-Sande \& Sande 2016:233). Knowledge transformation abilities are therefore a powerful tool for firms intending to undergo strategic transformation and attain competitive advantage (Ayadi, Hachaichi \& Feki 2017:544). Based on the arguments presented, it is appropriate to propose that firms that intend to develop customer-centric organisational systems must prioritise the development 
of their knowledge transformation capabilities; hence the following hypothesis is made:

$\mathbf{H}_{2}$ : There is a positive and significant relationship between knowledge transformation capacity and customer-oriented organisational systems.

\section{Technology operating capability and customer- oriented organisational systems}

The rapid technological transformation that has occurred globally has changed the business landscape, making it more connected, transparent and unpredictable. Novel wireless technologies have transformed business, operations and structures in both developed and developing countries (Rana et al. 2015:127). On a global scale the advent of new and dynamic technologies, such as social media platforms, is pushing firms to adopt customer-centric strategies as a way of sustaining long-term customer relationships and increasing valuable customer interactions (Ostrom et al. 2015:129). It is largely accepted that strategic operation of technology enables proper management of practices and processes that contribute to superior performance. On that note, firms with strong technological capability have been successful in transforming their operations for sustainable competitive advantage (Srivastava, Gnyawali \& Hatfield 2015:348). The use of technology improves the potential for a firm to identify opportunities, thus creating a strong basis for the formulation of firm strategies (Morone 1989:96). In a nutshell, the ability to operate pertinent technological acquisitions is an avenue for sustained corporate strategy formulation and reorientation for firms, both large and small, and against this background, the following hypothesis is made.

$\mathbf{H}_{3}$ : There is a positive and significant relationship between technology operating capability and customer-oriented organisational systems.

\section{Method}

A deductive quantitative research approach was used in this study to ascertain the influence of knowledge and technology management capabilities on the development of customercentric organisational systems. This study was conducted among SMEs in the 10 provinces of Zimbabwe that are members of the Small and Medium Enterprises Association of Zimbabwe. The study sample consisted of 832 SMEs from several sectors within the Zimbabwean economy. The sample was selected using a simple random sampling technique with the help of Randomizer software to ensure randomness. Of the 832 questionnaires sent out, 388 were returned and considered usable for data analysis, giving a response rate of $46.6 \%$. Probability sampling methods are preferred to non-probability sampling techniques in studies that are quantitative in nature, hence the decision to use simple random sampling. The questionnaire was distributed using the drop-off and pick-up approach (Dillman, Smyth \& Christian 2014:217) as attempts to employ the email questionnaire technique failed to yield positive results. The same SMEs who were contacted using email were contacted using the drop-off and pick-up approach. Additionally, this approach was chosen because it afforded the researcher an opportunity to present and clarify the research topic to the respondents. The questionnaire was designed with a five-point Likert scale with end points of 'strongly disagree' and 'strongly agree' as it was considered generally easy to use and produces more standardised scales for statistical evaluation. Structural equation modelling (SEM) was used for data analysis as this technique enables the drawing of causal inferences for a better understanding of the phenomenon under study. In SEM, measures of goodness of fit are undertaken to provide an evaluation of the whole model as opposed to the estimation on an equation-by-equation basis (Graafland 2018:275).

\section{Ethical considerations}

Ethical procedures were followed according to the University of Johannesburg ethics policy. To this end, before participating in the study respondents were made aware that they were under no obligation to participate and that if at any stage of the research they wish to withdraw their participation they were free to do so. Respondents were also assured that the study and its results will only be used for academic reasons and no other, and that their identity will be kept anonymous. The confidentiality of their expressed views was also guaranteed.

\section{Results}

\section{Firm demographics}

This study was conducted on a sample of 388 SMEs from various sectors of the Zimbabwean economy.

The characteristics of the firms in the sample are presented in Table 1. From the results presented in the table, the retail sector had the highest number of respondents, totalling 102,

TABLE 1: Firm demographics.

\begin{tabular}{|c|c|c|}
\hline Demographics & Frequency $(n)$ & Percentage (\%) \\
\hline \multicolumn{3}{|l|}{ Business sector } \\
\hline Manufacturing & 83 & 21.4 \\
\hline Retail & 102 & 26.3 \\
\hline Mining & 42 & 10.8 \\
\hline Tourism & 52 & 13.4 \\
\hline Agriculture & 47 & 12.1 \\
\hline Other & 62 & 16.0 \\
\hline Total & 388 & 100 \\
\hline \multicolumn{3}{|l|}{ Number of employees } \\
\hline $0-50$ & 204 & 52.6 \\
\hline $51-100$ & 66 & 17.0 \\
\hline $101-150$ & 49 & 12.6 \\
\hline Total & 388 & 100.0 \\
\hline \multicolumn{3}{|l|}{ Business turnover } \\
\hline$\$ 0-\$ 5000$ & 145 & 37.4 \\
\hline$\$ 5001-\$ 10000$ & 80 & 20.6 \\
\hline$\$ 10000-\$ 15000$ & 88 & 22.7 \\
\hline$\$ 15001$ and more & 75 & 19.3 \\
\hline Total & 388 & 100.0 \\
\hline \multicolumn{3}{|l|}{ Years in business } \\
\hline Less than 5 years & 164 & 42.3 \\
\hline Between 5 and 10 years & 118 & 30.4 \\
\hline More than 10 years & 106 & 27.3 \\
\hline Total & 388 & 100.0 \\
\hline
\end{tabular}


while the manufacturing sector had 83. There was lower participation from firms in other sectors like mining, tourism and agriculture. In terms of number of employees, the majority of participants had 50 and below (204 participants). This could be attributed to the fact that the economic downturn has forced firms to downsize operations, resulting in loss of jobs. Most of these SMEs have been in business for more than 5 years $(57.8 \%)$; however there was significant contribution from relatively new firms. In terms of turnover, most SMEs had a turnover of $\$ 5000$ and below $(37.4 \%)$, indicative of the constrained growth in the SME sector.

\section{Reliability and validity measures}

In this study, reliability and validity tests were carried out to verify the appropriateness of the measurement instrument and model. Reliability was tested using the Cronbach's alpha, and as per the recommended guidelines the Cronbach's alpha should be at least 0.70 for internal consistency to hold (Cronbach 1951:298).

In this study, internal consistency was met as the constructs' alpha values ranged between 0.729 and 0.775 , as presented in Table 2. The constructs' convergent validity and discriminant validity was also evaluated, and convergent validity was tested using the composite reliability, the average variance extracted (AVE) and item factor loadings. For convergent validity to hold, AVE values should be above 0.7 (very good), while 0.5 is considered acceptable (Fornell \& Larcker 1981:40). In relation to factor loadings, values of 0.5 or more are regarded as satisfactory, while for composite reliability a value more than or equal to 0.7 confers convergent validity (Hair, Anderson \& Tatham 1987:260). The composite reliability values for the constructs in this study ranged between 0.764 and 0.822 , and the AVEs between 0.514 and
0.547, proving convergent validity. All the item loadings were higher than the 0.50 yardstick (Table 2). Discriminant validity measures the extent to which measures of two factors are empirically discrete, and this was tested by comparing the square root of AVE and the interconstruct correlations. The square root of AVE for each construct should be greater than the interconstruct correlations and all other constructs for discriminant validity to hold (Fornell \& Larcker 1981:39). Therefore, the results from this study suggest satisfactory discriminant validity (Table 3).

Following the recommendations of Anderson and Gerbing (1988:411), a two-stage SEM approach was employed to test the significance of all coefficients and the hypotheses made. The measurement model was examined initially to test for causal relationships between the observed and latent variables in AMOS 24. The second stage involved testing the structural model using path analysis to explain the causal association between the constructs.

\section{Measurement and structural model analysis}

To evaluate the goodness of fit of both the measurement and the structural models, the chi-square and degrees of freedom ration, root mean square error of approximation (RMSEA) and the comparative fit index (CFI) were used, as these provided adequate distinctive measures for assessing the models.

TABLE 3: Square root of average variance extracted and correlations of constructs.

\begin{tabular}{lccccc}
\hline Variable & AVE & KAC & KTC & TOC & CCOS \\
\hline Knowledge acquisition capability & 0.547 & 0.740 & - & - & - \\
Knowledge transformation capability & 0.538 & 0.612 & 0.733 & - & - \\
Technology operating capability & 0.536 & 0.696 & 0.617 & 0.732 & - \\
Customer-centric organisational systems & 0.514 & 0.658 & 0.677 & 0.718 & 0.717 \\
\hline
\end{tabular}

Note: Bold figures on the diagonal are the square roots of AVE.

AVE, average variance extracted; KAC, knowledge acquisition capability; KTC, knowledge transformation capability; TOC, technology operating capability; CCOS, customer-centric organisational systems.

TABLE 2: The reliability, validity, standardised loadings and fit statistics.

\begin{tabular}{|c|c|c|c|}
\hline Construct item & Standard estimate & $\mathbf{R 2}$ & Error estimate \\
\hline \multicolumn{4}{|l|}{ Knowledge acquisition capability ( $\alpha=0.739$, CR $=0.764$, AVE $=0.547)$} \\
\hline Our firm has frequent interactions with other firms to acquire new knowledge. & 0.705 & 0.497 & 0.503 \\
\hline Our employees regularly visit other firms in the industry. & - & - & - \\
\hline We collect industry information through informal means. & 0.711 & 0.506 & 0.494 \\
\hline Our firm periodically meets with third parties to acquire new knowledge. & 0.745 & 0.550 & 0.445 \\
\hline \multicolumn{4}{|l|}{ Knowledge transformation capability $(\alpha=0.744, \mathrm{CR}=0.748, \mathrm{AVE}=0.538)$} \\
\hline Our firm considers the consequences of changing market demands. & 0.742 & 0.551 & 0.449 \\
\hline Our employees record newly acquired knowledge for future reference. & 0.769 & 0.591 & 0.409 \\
\hline Our firm recognises the usefulness of new external knowledge. & 0.638 & 0.407 & 0.593 \\
\hline Our employees rarely share practical experiences. & 0.777 & 0.604 & 0.396 \\
\hline \multicolumn{4}{|l|}{ Technology operating capability ( $\alpha=0.775, \mathrm{CR}=0.822, \mathrm{AVE}=0.536$ ) } \\
\hline We manufacture our goods and services using advanced technology. & 0.775 & 0.601 & 0.399 \\
\hline Our firm has more skilful technical staff and operational workers. & 0.780 & 0.608 & 0.392 \\
\hline We have less operation discontinuity. & 0.781 & 0.610 & 0.390 \\
\hline \multicolumn{4}{|l|}{ Customer-centric org. systems $\alpha=0.729, \mathrm{CR}=0.809$, AVE $=0.514$ ) } \\
\hline Our processes are designed to enhance the quality of customer interactions. & 0.768 & 0.590 & 0.410 \\
\hline We focus on customer needs when designing business processes. & 0.712 & 0.507 & 0.493 \\
\hline We organise our firm around customer-based groups rather than products. & 0.732 & 0.536 & 0.464 \\
\hline Functional areas coordinate to enhance the quality of customers' interactions. & 0.654 & 0.428 & 0.572 \\
\hline
\end{tabular}


The results show that both the measurement and structural models exhibited satisfactory fit, and the models could be relied upon. The $\chi^{2} / \mathrm{df}$ ratio for the measurement model and structural model was 1.862 and 1.461, respectively, and hence satisfactory. The CFI for both models were within the acceptable yardstick of 0.90 or more $(0.990$ and 0.966 for the measurement model and structural model, respectively) and so was the RMSEA. Both RMSEA values were below 0.05 (0.046 and 0.038), as recommended by Bentler (1990:238). Irrefutably, goodness of fit was achieved for both the measurement and the structural model as the results of the confirmatory factor analysis indicated.

\section{Path analysis and hypothesis testing}

Structural equation modelling was conducted in AMOS v24 to test the structural associations proposed in Figure 1 $\left(\mathrm{H}_{1}\right.$ through $\left.\mathrm{H}_{3}\right)$. Table 3 provides a summary of the standardised structural coefficients for all hypotheses made in this study.

Results presented in Table 4 show that knowledge acquisition capability, knowledge transformation capability and TOC all have a significant and positive effect on customer-centric organisational systems. The path coefficient serves as an indicator of the strength of the relationship between variables, and the $t$-values (critical ratio) of +1.96 or greater (and -1.96 or lower) denote the statistical significance of the related constructs, subsequently confirming the hypotheses of the study. Hypothesis 1 proposed that there is a positive and significant relationship between knowledge acquisition capability and customer-centric organisational systems. The results in this study support this hypothesis $(\beta=0.446$; $t$-statistic $=26.53)$. In line with Hypothesis 1 , Hypothesis 2 shows that knowledge transformation capability has a significant and positive relationship with customer-centric

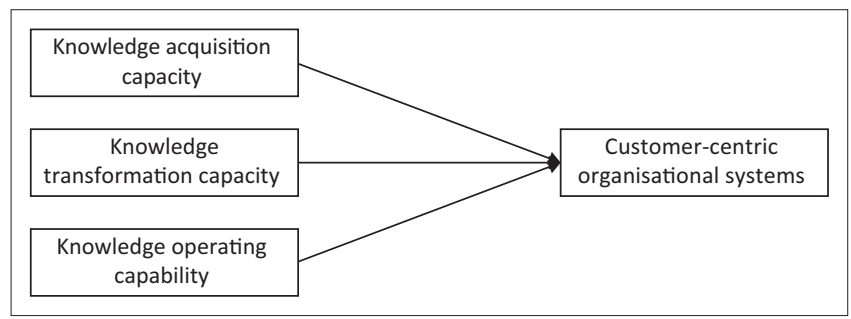

FIGURE 1: Conceptual model.

TABLE 4: Test of goodness of fit.

\begin{tabular}{lccc}
\hline Variable & $\mathbf{X}^{2} / \mathbf{d f}$ & CFI & RMSEA \\
\hline Recommended & $\leq 2.000$ & $\geq 0.900$ & $\leq 0.050$ \\
Measurement model & 1.862 & 0.990 & 0.046 \\
Structural model & 1.461 & 0.966 & 0.038 \\
\hline
\end{tabular}

$\mathrm{df}$, degrees of freedom; CFI, comparative fit index; RMSEA, root mean square error of approximation organisational systems, as the regression path coefficient expectedly showed a beta value of 0.141 and a $t$-statistic of 6.64 at a significance level of 0.001 . Hypothesis 3 concerned the potential influence of TOC on customer-centric organisational systems. The analysis showed that there is a significant and positive relationship between the variables $(\beta=0.910 ; t$-statistic $=15.43)$. Of interest is the fact that the TOC has the highest positive influence on customer-centric organisation systems (CCOS). This could be viewed as an affirmation that operation of technology enables proper management of practices transformation of organisational systems for sustainable competitive advantage (Srivastava et al. 2015:348). The findings about the causal estimates corresponding to the hypothesised SEM paths and the resultant regression weights are presented in Table 4.

\section{Conclusions and implications}

Knowledge management and technology have been accepted as central to firms' processes, culture, human resources and the ability to create other organisational capabilities for competitive advantage (Wang et al. 2013:60). Based on a survey and quantitative analysis of data from 388 SMEs in Zimbabwe, the study found that there are positive relationships between the two dimensions of knowledge management capability and one technological competence dimension. Thus, firms should consider knowledge capabilities and technological competences as drivers to help them achieve some customer-oriented systems and consequently yield superior performance in line with the propositions of Gebauer and Kowalkowski (2012:527). Because external knowledge searches have become progressively significant for SMEs to attain and maintain a competitive advantage, the study findings demonstrate that knowledge acquisition and transformation are also essential for firms to create customer-oriented organisational systems.

This study contributes to the present literature stream on customer orientation and customer centrism by highlighting knowledge acquisition capabilities, knowledge transformation capability and TOC, which SMEs can leverage to nurture their customer-centric organisational systems. The extant literature has predominantly focussed on the notions of absorptive capacity and technological competence as unified constructs (e.g. Cohen \& Levinthal 1990:128), and limited, inconclusive research has examined the role of the individual dimension of both absorptive capacity and technological competence. In disparity with extant literature, this study decomposed the two notions, absorptive capacity and technological competence, thereby giving a theoretically and empirically augmented view of the constructs. The study additionally provided empirical evidence on the

TABLE 5: Hypothesised relationships, standardised regression weights and $p$-values.

\begin{tabular}{|c|c|c|c|c|c|}
\hline Variable & & Estimate & $t$-statistic & $p$ & Hypothesis \\
\hline $\mathrm{H}_{1}$ & Knowledge acquisition capability $\rightarrow$ customer-centric organisational systems & 0.411 & 26.53 & $*$ & Accepted \\
\hline $\mathrm{H}_{2}$ & Knowledge transformation capability $\rightarrow$ customer-centric organisational systems & 0.141 & 6.64 & $*$ & Accepted \\
\hline $\mathrm{H}_{3}$ & Technology operating capability $\rightarrow$ customer-centric organisational systems & 0.910 & 15.43 & * & Accepted \\
\hline
\end{tabular}

Note: Significance levels $*, p<0.001$ 
complementary role of knowledge management capabilities and TOCs in empowering the creation of customer-centric organisational systems.

This study adds merit to the notion that knowledge acquisition and transformation capabilities and TOC lead to the development of new organisational competencies and organisational transformation. It provides empirical support for the both the knowledge-based view and the dynamic capabilities theory, as it confirms that the foundation for organisational transformation and capabilities development lies in the ability to acquire, recombine and operate both technology and knowledge, as advocated by Grant (1996:110). In terms of knowledge management capabilities and technology operating practices, the study findings have significant implications for managers. Owners and managers of SMEs should place superior emphasis on consolidating their knowledge acquisition and transformation capabilities and their TOCs. These are important tools for transforming and developing their organisational systems into customer centrism, as this could be instrumental in facilitating a competitive edge as advocated by Garrido-Moreno and Padilla-Meléndez (2011:440). This study provides a platform for potential empirical investigation trajectories as there is still need for understanding the influence of other absorptive capacity and technological competence sub constructs.

\section{Acknowledgements Competing interests}

The authors declare that they have no financial or personal relationships that may have inappropriately influenced them in writing this article.

\section{Authors' contributions}

W.M. conducted the literature search, collected the data and worked on the draft. D.P. supervised W.M.'s work, polished the data analysis and refined the article for submission.

\section{Disclaimer}

The views expressed in this article are those of the authors and do not represent an official position of the institution or funder.

\section{References}

Åkerman, N., 2015, 'Knowledge-acquisition strategies and the effects on market knowledge-profiling the internationalizing firm', European Management Journal 33(2), 79-88. https://doi.org/10.1016/j.emj.2014.06.003

Anderson, J.C. \& Gerbing, D.W., 1988, 'Structural equation modeling in practice A review and recommended two-step approach', Psychological Bulletin 103(3), 411. https://doi.org/10.1037/0033-2909.103.3.411

Ayadi, R., Hachaichi, Y. \& Feki, J., 2017, 'MOT knowledge model integration rules for knowledge warehousing', Procedia Computer Science 112, 544-553. https://doi. org/10.1016/j.procs.2017.08.164

Behfar, S.K., Turkina, E. \& Burger-Helmchen, T., 2018, 'Knowledge management in OSS communities: Relationship between dense and sparse network structures', International Journal of Information Management 38(1), 167-174. https://doi. org/10.1016/j.ijinfomgt.2017.09.004.

Bentler, P.M., 1990, 'Comparative fit indexes in structural models', Psychological Bulletin 107(2), 238-246.
Bomani, M., Fields, Z. \& Derera, E., 2015, 'Historical overview of small and medium enterprise policies in Zimbabwe', Journal of Social Sciences 45(2), 113-129.

Bortoluzzi, G., Kadic-Maglajlic, S., Arslanagic-Kalajdzic, M. \& Balboni, B., 2018, 'Innovativeness as a driver of the international expansion of developing markets' firms: Evidence of curvilinear effects', International Marketing Review 35(2), 215-235. https://doi.org/10.1108/IMR-11-2015-0258

Brodie, R.J., Hollebeek, L.D., Jurić, B. \& Ilić, A., 2011, 'Customer engagement: Conceptual domain, fundamental propositions, and implications for research' Journal of Service Research 14(3), 252-271. https://doi.org/10.1177/10946705 11411703

Chan, K.W., Yim, C.K. \& Lam, S.S., 2010, 'Is customer participation in value creation a double-edged sword? Evidence from professional financial services across cultures', Journal of Marketing 74(3), 48-64. https://doi.org/10.1509/jmkg.74.3.048

Chang, Y.Y., Gong, Y. \& Peng, M.W., 2012, 'Expatriate knowledge transfer, subsidiary absorptive capacity, and subsidiary performance', Academy of Management Journal 55(4), 927-948. https://doi.org/10.5465/amj.2010.0985

Chiang, W.Y., 2018, 'Identifying high-value airlines customers for strategies of online marketing systems: An empirical case in Taiwan', Kybernetes 47(3), 525-538. https://doi.org/10.1108/K-12-2016-0348

Cohen, W.M. \& Levinthal, D.A., 1990, 'The implications of spillovers for R\&D investment and welfare: A new perspective', Administrative Science Quarterly 35(1990), 128-152. https://doi.org/10.2307/2393553

Cronbach, L.J., 1951, 'Coefficient alpha and the internal structure of tests', Psychometrika 16, 297-334.

Darbanhosseiniamirkhiz, M. \& Wan Ismail, W.K., 2012, 'Advanced manufacturing technology adoption in SMEs: An integrative model', Journal of Technology Management \& Innovation 7(4), 112-120. https://doi.org/10.4067/S0718-2724 2012000400009

Davenport, T.H., 2005, Thinking for a living: How to get better performances and results from knowledge workers, Harvard Business Press, Boston, MA

De Arruda, H.F., Silva, F.N., Costa, L.D.F. \& Amancio, D.R., 2017, 'Knowledge acquisition: A complex networks approach', Information Sciences 421, 154-166. https://doi. org/10.1016/j.ins.2017.08.091

Dillman, D.A., Smyth, J.D. \& Christian, L.M., 2014, Internet, phone, mail, and mixedmode surveys: The tailored design method, John Wiley \& Sons, Hoboken, NJ.

Enz, M.G. \& Lambert, D.M., 2015, 'Measuring the financial benefits of cross-functional integration influences management's behavior', Journal of Business Logistics 36(1), 25-48. https://doi.org/10.1111/jbl.12068

Fornell, C. \& Larcker, D.F., 1981, 'Evaluating structural equation models with unobservable variables and measurement error', Journal of Marketing Research 18(1), 39-50. https://doi.org/10.1177/002224378101800104

Foroudi, P., Gupta, S., Sivarajah, U. \& Broderick, A., 2018, 'Investigating the effects of smart technology on customer dynamics and customer experience', Computers in Human Behavior 80, 271-282. https://doi.org/10.1016/j.chb.2017.11.014

Frankenberger, K., Weiblen, T. \& Gassmann, O., 2013, 'Network configuration, customer centricity, and performance of open business models: A solution provider perspective', Industrial Marketing Management 42(5), 671-682. https:// doi.org/10.1016/j.indmarman.2013.05.004

Garrido-Moreno, A. \& Padilla-Meléndez, A., 2011, 'Analyzing the impact of knowledge management on CRM success: The mediating effects of organizational factors', International Journal of Information Management 31(5), 437-444. https://doi. org/10.1016/j.ijinfomgt.2011.01.002

Gebauer, H. \& Kowalkowski, C., 2012, 'Customer-focused and service-focused orientation in organizational structures', Journal of Business \& Industrial Marketing 27(7), 527-537. https://doi.org/10.1108/08858621211257293

Graafland, J.J., 2018, 'Ecological impacts of the ISO14001 certification of small and medium sized enterprises in Europe and the mediating role of networks', Journal of Cleaner Production 174, 273-282. https://doi.org/10.1016/j.jclepro.2017.10.322

Grant, R.M., 1996, 'Toward a knowledge-based theory of the firm', Strategic Management Journal 17(S2), 109-122. https://doi.org/10.1002/smj.4250171110

Grönroos, C. \& Voima, P., 2013, 'Critical service logic: Making sense of value creation and co-creation', Journal of the Academy of Marketing Science 41(2), 133-150. https://doi.org/10.1007/s11747-012-0308-3

Güçdemir, H. \& Selim, H., 2017, 'Customer centric production planning and control in job shops: A simulation optimization approach', Journal of Manufacturing Systems 43, 100-116. https://doi.org/10.1016/j.jmsy.2017.02.004

Hagedoorn, J. \& Wang, N., 2012, 'Is there complementarity or substitutability between internal and external R\&D strategies?' Research Policy 41(6), 10721083. https://doi.org/10.1016/j.respol.2012.02.012

Harison, E. \& Boonstra, A., 2008, 'Reaching new altitudes in e-commerce: Assessing the performance of airline websites', Journal of Air Transport Management 14(2), 92-98. https://doi.org/10.1016/j.jairtraman.2008.02.002

Hair, J.F., Anderson, R.E. \& Tatham, R.L., 1987, Multivariate data analysis, Macmillan: New Jersey.

Homburg, C., Workman, J.P. Jr. \& Jensen, O., 2000, 'Fundamental changes in marketing organization: The movement toward a customer-focused organizational structure' Journal of the Academy of Marketing Science 28(4), 459-478. https://doi. org/10.1177/0092070300284001

Hsieh, Y.C., Chiu, H.C., Tang, Y.C. \& Lin, W.Y., 2018, 'Does raising value co-creation increase all customers' happiness?', Journal of Business Ethics 152(4), 1053-1067. https://doi.org/10.1007/s10551-016-3293-5

Hsieh, Y.H. \& Chou, Y.H., 2018, 'Modeling the impact of service innovation for small and medium enterprises: A system dynamics approach', Simulation Modelling Practice and Theory 82, 84-102. https://doi.org/10.1016/j.simpat.2017.12.004 
Kayvanfar, V., Husseini, S.M., Sajadieh, M.S. \& Karimi, B., 2018, 'A multi-echelon multiproduct stochastic model to supply chain of small-and-medium enterprises in industrial clusters', Computers \& Industrial Engineering 115, 69-79. https://doi. industrial clusters', Computers
org/10.1016/j.cie.2017.11.003

Kocoglu, I., Akgün, A.E. \& Keskin, H., 2015, 'The differential relationship between absorptive capacity and product innovativeness: A theoretically derived framework', International Business Research 8(7), 108. https://doi.org/10.5539/ ibr.v8n7p108

Korhonen-Sande, S. \& Sande, J.B., 2016, 'Improving customer knowledge transfer in industrial firms: How does previous work experience influence the effect of reward systems?', Journal of Business \& Industrial Marketing 31(2), 232-246. https://doi.org/10.1108/JBIM-03-2014-0048

Krome, M.A., 2014, 'Knowledge transformation: A case for workforce diversity' Journal of Diversity Management (Online) 9(2), 103. https://doi.org/10.19030/ jdm.v9i2.8975

Mahembe, E.E. \& Odhiambo, N.M., 2016, 'Does foreign direct investment cause economic growth? A dynamic panel data analysis for SADC countries', International Journal of Emerging Markets 11(3), 316-332. https://doi.org/10.1108/ IJOEM-06-2014-0084

Malshe, A. \& Friend, S.B., 2018, 'Initiating value co-creation: Dealing with non-receptive customers', Journal of the Academy of Marketing Science 46(5), 895-920. https:// doi.org/10.1007/s11747-018-0577-6

Masaka, D., 2013, 'Pitting market economy against planned economy: A false dichotomy in Zimbabwe (1980-2011)', Journal of Black Studies 44(3), 314-329. https://doi.org/10.1177/0021934713482583

Mbizi, R., Hove, L., Thondhlana, A. \& Kakava, N., 2013, 'Innovation in SMEs: A review of its role to organisational performance and SMEs operations sustainability', Interdisciplinary Journal of Contemporary Research in Business 4(11), 370-389.

Minguela-Rata, B., Fernández-Menéndez, J. \& Fossas-Olalla, M., 2014, 'Cooperation with suppliers, firm size and product innovation', Industrial Management \& Data Systems 114(3), 438-455. https://doi.org/10.1108/IMDS-08-2013-0357

Mishra, D., Aydin, S., Mishra, A. \& Ostrovska, S., 2018, 'Knowledge management in requirement elicitation: Situational methods view', Computer Standards \& Interfaces 56, 49-61. https://doi.org/10.1016/j.csi.2017.09.004

Montignies, F., Nosulenko, V. \& Parizet, E., 2010, 'Empirical identification of perceptual criteria for customer-centred design. Focus on the sound of tapping on the dashboard when exploring a car', International Journal of Industrial Ergonomics 40(5), 592-603. https://doi.org/10.1016/j.ergon.2010.04.004

Morone, J., 1989, 'Strategic use of technology', California Management Review 31(4), 91-110. https://doi.org/10.2307/41166584

Ngwenya, B., Pelser, T. \& Chivaura, T., 2018, 'Perceptions of post-multicurrency regime financial inclusion confidence challenges in Zimbabwe', South African Journal of Economic and Management Sciences 21(1), 1-15. https://doi.org/10.4102/ sajems.v21i1.1837

Operti, E. \& Carnabuci, G., 2014, 'Public knowledge, private gain: The effect of spillover networks on firms' innovative performance', Journal of Management 40(4), 1042-1074. https://doi.org/10.1177/0149206311422448

Ostrom, A.L., Parasuraman, A., Bowen, D.E., Patricio, L. \& Voss, C.A., 2015, 'Service research priorities in a rapidly changing context', Journal of Service Research 18(2), 127-159. https://doi.org/10.1177/1094670515576315

Postigo-Boix, M. \& Melús-Moreno, J.L., 2018, 'A social model based on customers' profiles for analyzing the churning process in the mobile market of data plans', Physica A: Statistical Mechanics and Its Applications 496, 571-592. https://doi. org/10.1016/j.physa.2017.12.121

Quintas, P., Lefrere, P. \& Jones, G., 1997, 'Knowledge management: A strategic agenda', Long Range Planning 30(3), 385-391. https://doi.org/10.1016/S00246301(97)90252-1
Rana, N.P., Dwivedi, Y.K., Williams, M.D. \& Weerakkody, V., 2015, 'Investigating success of an e-government initiative: Validation of an integrated IS success model', of an e-government initiative: Validation of an integrated IS success model,
Information Systems Frontiers 17(1), 127-142. https://doi.org/10.1007/s10796Information

Rundquist, J., 2012, 'The ability to integrate different types of knowledge and its effect on innovation performance', International Journal of Innovation Management 16(2), 1250014. https://doi.org/10.1142/S1363919612003794

Salomon, R. \& Jin, B., 2010, 'Do leading or lagging firms learn more from exporting?', Strategic Management Journal 31(10), 1088-1113. https://doi.org/10.1002/ smj. 850

Simwayi, M. \& Haseed, M., 2011, 'The role of financial intelligence units in combating money laundering: A comparative analysis of Zambia, Zimbabwe and Malawi' Journal of Money Laundering Control 15(1), 112-134. https://doi.org/10.1108/ 13685201211194754

Smirnova, M.M., Rebiazina, V.A. \& Frösén, J., 2017, 'Customer orientation as a multidimensional construct: Evidence from the Russian markets', Journal of Business Research 86, 457-467. https://doi.org/10.1016/j.jbusres.2017.10.040

Sobanke, V., Adegbite, S., Ilori, M. \& Egbetokun, A., 2014, 'Determinants of technological capability of firms in a developing country', Procedia Engineering 69, 991-1000. https://doi.org/10.1016/j.proeng.2014.03.081

Srivastava, M.K., Gnyawali, D.R. \& Hatfield, D.E., 2015, 'Behavioral implications of absorptive capacity: The role of technological effort and technological capability in leveraging alliance network technological resources', Technological Forecasting and Social Change 92, 346-358. https://doi.org/10.1016/j.techfore. 2015.01.010

Thakur, R. \& Workman, L., 2016, 'Customer portfolio management (CPM) for improved customer relationship management (CRM): Are your customers platinum, gold silver, or bronze?', Journal of Business Research 69(10), 4095-4102. https://doi. org/10.1016/j.jbusres.2016.03.042

Todorova, G. \& Durisin, B., 2007, 'Absorptive capacity: Valuing a reconceptualization' Academy of Management Review 32(3), 774-786. https://doi.org/10.5465/ amr.2007.25275513

Wang, D., Li, X.R. \& Li, Y., 2013, 'China's “smart tourism destination” initiative: A taste of the service-dominant logic', Journal of Destination Marketing \& Management 2(2), 59-61. https://doi.org/10.1016/j.jdmm.2013.05.004

Wu, I.L. \& Chen, J.L., 2014, 'Knowledge management driven firm performance: The roles of business process capabilities and organizational learning', Journal of Knowledge Management 18(6), 1141-1164. https://doi.org/10.1108/JKM-05Knowledge

Yeung, C.L., Wang, W.M., Cheung, C.F., Tsui, E., Setchi, R. \& Lee, R.W., 2018 , 'Computational narrative mapping for the acquisition and representation of lessons learned knowledge', Engineering Applications of Artificial Intelligence 71 lessons learned knowledge', Engineering Applications of A

Youssef, Y.M.A., Johnston, W.J., AbdelHamid, T.A., Dakrory, M.I. \& Seddick, M.G.S. 2018, 'A customer engagement framework for a B2B context', Journal of Business \& Industrial Marketing 33(1), 145-152. https://doi.org/10.1108/JBIM-11-2017\& Ind 0286

Zahra, S.A. \& George, G., 2002, 'Absorptive capacity: A review, reconceptualization, and extension', Academy of Management Review 27(2), 185-203. https://doi. org/10.5465/amr.2002.6587995

Zhai, Y.M., Sun, W.Q., Tsai, S.B., Wang, Z., Zhao, Y. \& Chen, Q., 2018, 'An empirical study on entrepreneurial orientation, absorptive capacity, and SMEs' innovation performance: A sustainable perspective', Sustainability 10(2), 314-328. https:// doi.org/10.3390/su10020314

Zhou, K.Z. \& Li, C.B., 2012, 'How knowledge affects radical innovation: Knowledge base, market knowledge acquisition, and internal knowledge sharing', Strategic Management Journal 33(9), 1090-1102. https://doi.org/10.1002/smj.1959 